\title{
Novel determination of the crystallinity of syndiotactic polystyrene using FTIR spectrum
}

\author{
Hew-Der Wu, Shoei-Chin Wu, I-Der Wu, Feng-Chih Chang* \\ Institute of Applied Chemistry, National Chiao-Tung University, Hsinchu 30050, Taiwan, ROC
}

Received 20 June 2000; received in revised form 23 October 2000; accepted 13 November 2000

\begin{abstract}
The crystallinity and crystallization behavior of syndiotactic polystyrene (s-PS) $\alpha$ - and $\beta$-crystals have been thoroughly examined using the Fourier Transform Infrared (FTIR). It is shown that absorptivity ratio of respective absorbances of " $\alpha$-crystal/amorphous, $a_{\alpha}$ " and " $\beta$ crystal/amorphous, $a_{\beta}$ " can be quantitatively determined using FTIR spectra ranging from 865 to $820 \mathrm{~cm}^{-1}$. Results from curve fitting show that both absorptivity ratios of $a_{\alpha}$ and $a_{\beta}$ are $0.178 \pm 0.005$ and $0.272 \pm 0.005$ for $\alpha$ - and $\beta$-crystal absorbances, respectively. The crystallization rate and crystallinity of $\alpha$-crystal calculated from the absorptivity ratios are higher than that of $\beta$-crystal crystallized at $240^{\circ} \mathrm{C}$ for the same isothermal duration in thin film sample. The formation of $\beta$-crystal is thermodynamically more favorable while of $\alpha$-crystal is kinetically more favorable from FTIR spectra. (C) 2001 Elsevier Science Ltd. All rights reserved.
\end{abstract}

Keywords: s-PS; Crystallinity; FTIR

\section{Introduction}

It is well known that the polymorph of syndiotacticpolystyrene (s-PS) is rather complicated. As a matter of fact, s-PS possesses various combinations of four different crystalline unit cells $(\alpha, \beta, \gamma, \delta)$ depending on thermal history and/ or solution treatment [1-3]. Typically, $\alpha$ - and $\beta$-crystals can be obtained by melt- and cold- crystallizations, and the $\beta$ crystal is considered to be favored over the $\alpha$-crystal in s-PS at higher temperature of crystallization. Recently, the formation of the $\beta$-crystal has been found to be favored in s-PS associated with high pressure [4] or blending with clay [5]. The polymorph in the s-PS is interpreted as the results of competition between thermodynamics and kinetics during crystallization process. Although, numerous studies have placed on the subject of s-PS crystallization [1-5], quantitative in-depth view in particular crystal forms in s-PS has yet to be fully understood.

It has been well recognized that the melt-crystallized s-PS at higher temperature (over $240^{\circ} \mathrm{C}$ ) results in only $\beta$-crystal [6]. Our previous studies have demonstrated that the $\alpha$-crystal is formed exclusively in thin film cold-crystallization and the crystal transformation (into $\beta$-crystal) does not occur even at as high as $264^{\circ} \mathrm{C}$ due to physical hindrance [7]. However, the transformation of $\alpha$ - to $\beta$-crystal does occur

\footnotetext{
* Corresponding author. Tel.: +886-35-712-121; fax: +886-35-723-764
}

E-mail address: changfc@cc.ntcu.edu.tw (F.-C. Chang). in bulk specimen because the $\alpha$-crystal is less favored at higher temperature [1,6,7]. The relative fraction of $\alpha$ - and $\beta$-crystal depends not only on the thermal history but also on the thickness of sample.

The application of Fourier Transform Infrared (FTIR) spectroscopic techniques to assess polymer crystallinity has been done for many years [8]. IR has proven to be a powerful tool for the characterization of polymers. It is complementary to other techniques in providing detailed information concerning the crystallinity and conformation of polymers with advantages of nondestructive and fast measurement [9-12]. The changes in crystallinity and crystal conformation can be characterized through the identification of the IR spectral features in intensity, bandwidth, and position.

In this study, FTIR is used to identify and quantify the crystallization behavior of both $\alpha$ - and $\beta$-crystals of s-PS. Two goals are pursued: (1) calculating the absorptivity ratios of " $\alpha$-crystal/amorphous" and " $\beta$-crystal/amorphous" from FTIR spectra; and (2) more important, calculating the crystallinity of $\alpha$ - and $\beta$-crystals and sorts out their crystallization behavior in quantitative manner.

\section{Material and experimental section}

The s-PS was kindly donated by the Industrial Technology and Research Institute (ITRI) of Taiwan, which was 
Table 1

the specific characterized absorbance of s-PS in IR spectrum ranging from 940-820 cm ${ }^{-1}$ ("s", "m", and "w" represents for the "strong", "middle" and "weak" absorbances in IR spectrum, respectively)

\begin{tabular}{ll}
\hline Morphology & Position of absorbance $\left(\mathrm{cm}^{-1}\right)$ \\
\hline Amorphous phase & $905(\mathrm{~s}), 841(\mathrm{~m})$ \\
$\alpha$-form crystal & $901(\mathrm{~s}), 851(\mathrm{w})$ \\
$\beta$-form crystal & $911(\mathrm{~s}), 858(\mathrm{w})$
\end{tabular}

used without further purification. The chemical structure of the s-PS consists of $[\mathrm{rr}]=99 \%$ that was identified by the solution ${ }^{13} \mathrm{C}$ NMR spectrum for solution of s-PS with $M_{\mathrm{n}}=56,000$ [13].

A s-PS thin film sample was prepared by mixing thoroughly s-PS particles (diameter less than $10 \mu \mathrm{m}$ obtained from precipitation) and $\mathrm{KBr}$ powder (s-PS/ $\mathrm{KBr}=10 / 90$ by weight). The mixture was then compression-molded into disks under pressure of 600 psi. These small s-PS particles are dispersed uniformly and separatively within $\mathrm{KBr}$ matrix. The s-PS bulk sample was prepared by the same procedure as thin film sample, except that the s-PS particles with diameter of around $100 \mu \mathrm{m}$ were obtained by mechanical grind.

Isothermal cold- and melt-crystallizations of various time durations were performed on samples in an environmental chamber equipped with a temperature programmable controller to an accuracy of $\pm 0.1^{\circ} \mathrm{C}$. The s-PS sample was pretreated at $320^{\circ} \mathrm{C}$ for $20 \mathrm{~min}$ to eliminate the residual crystal memory in the melt, and then quenched by liquid nitrogen to obtain the amorphous (crystal-free) s-PS as the starting material for cold-crystallization. For melt-crystallization, s-PS was heated to $320^{\circ} \mathrm{C}$ and quickly cooled

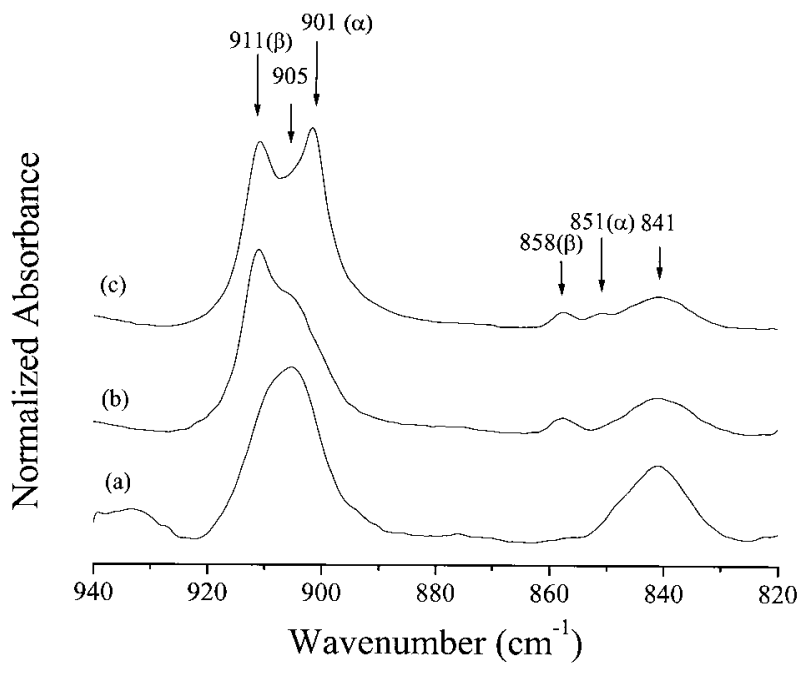

Fig. 1. The characteristic infrared band of neat s-PS ranging from 940 to $820 \mathrm{~cm}^{-1}$ : (a) quenched s-PS; (b) melt-crystallized s-PS at $240^{\circ} \mathrm{C}$ for $240 \mathrm{~min}$; (c) sample in (b) heating scan up to $264^{\circ} \mathrm{C}$ from $30^{\circ} \mathrm{C}$ with $10^{\circ} \mathrm{C} / \mathrm{min}$, then quenched by liquid nitrogen.

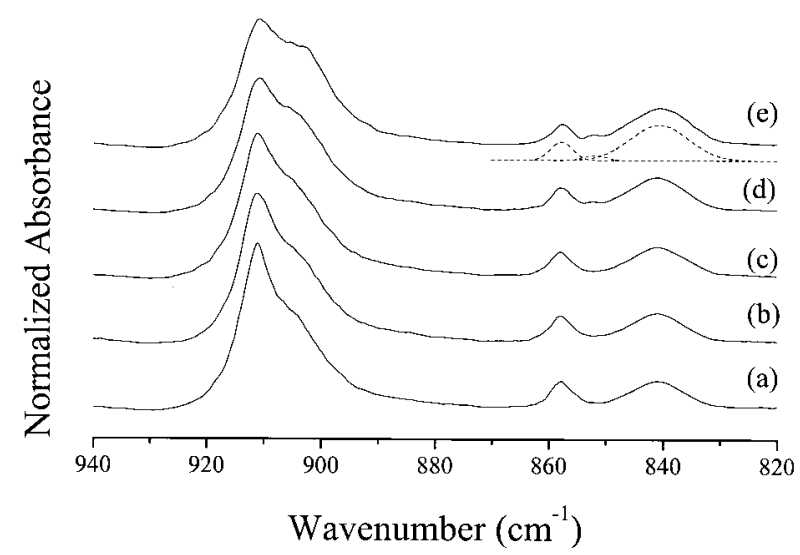

Fig. 2. FTIR spectra of s-PS bulk samples ranging from 865 to $820 \mathrm{~cm}^{-1}$ having cooled at various rates from $-1{ }^{\circ} \mathrm{C} / \mathrm{min}$ to $-100^{\circ} \mathrm{C} / \mathrm{min}$. (a) -1 , (b) -5 , (c) -10 , (d) -40 , (e) $-100^{\circ} \mathrm{C} / \mathrm{min}$, the dashed lines represent the result of curve-fitting of (e) ranging between 865 and $820 \mathrm{~cm}^{-1}$.

$\left(-100^{\circ} \mathrm{C} / \mathrm{min}\right)$ to $240^{\circ} \mathrm{C}$ for different durations; then quenched by liquid nitrogen. For cold-crystallization, the quenched s-PS sample, was heated up to $240^{\circ} \mathrm{C}$ with a rate of $100^{\circ} \mathrm{C} / \mathrm{min}$ and maintained at $240^{\circ} \mathrm{C}$ isothermally for different durations; then quenched by liquid nitrogen. Cooled s-PS samples from the melt were obtained by cooling from 320 to $30^{\circ} \mathrm{C}$ with different rates.

Crystal forms and crystallinity of the s-PS sample were characterized by infrared spectroscopy (Nicolet AVATAR 320 FTIR spectrometer, USA) with resolution of $1.0 \mathrm{~cm}^{-1}$

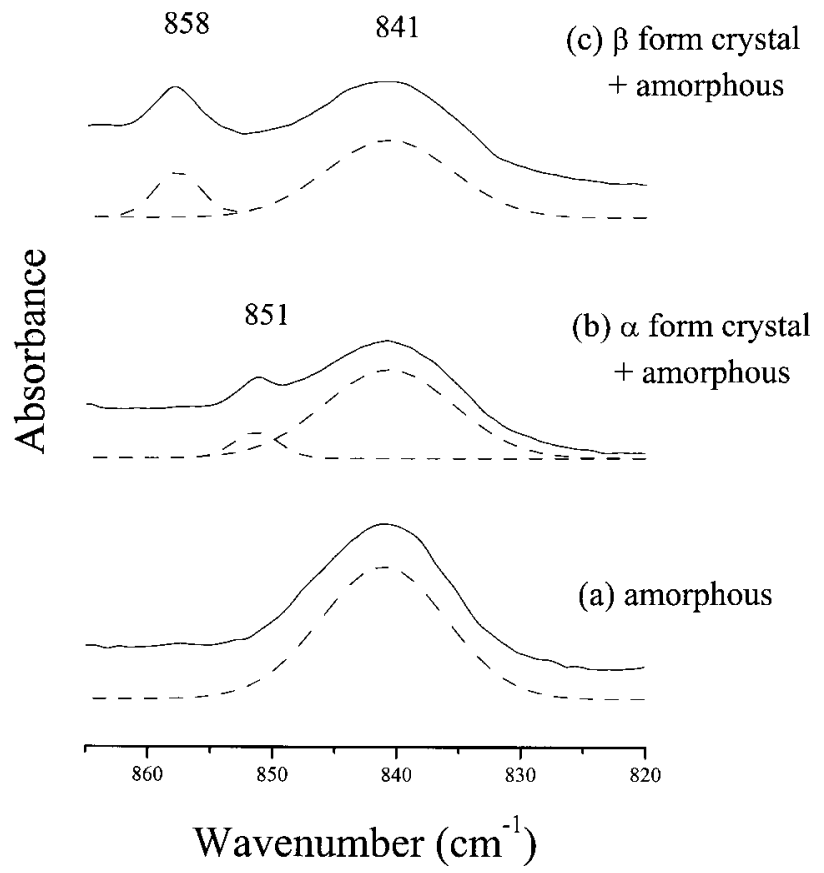

Fig. 3. FTIR spectra of: (a) quenched; (b) cold-crystallized; (c) melt-crystallized s-PS thin film sample at $240^{\circ} \mathrm{C}$ for arbitrary duration using the same s-PS sample. 
at $30^{\circ} \mathrm{C}$. The frequency scale of FTIR was internally calibrated using a $\mathrm{He}-\mathrm{Ne}$ laser and 32 scans were single-averaged to reduce the noise. The spectral baselines were offset to produce a clear indication of changes throughout the different thermal history. The peak position and intensity of the peak at $1602 \mathrm{~cm}^{-1}$ (corresponding to benzene ring) is found to be unaffected by varying the chain conformation or crystallinity. All peak areas in the measured range were normalized referring to the area of the $1602 \mathrm{~cm}^{-1}$ peak. This approach provides a quick and reliable method to identify and quantify crystal forms present in s-PS sample. All FTIR spectra were measured under nitrogen atmosphere to minimize the effects of $\mathrm{CO}_{2}$ and moisture.

\section{Results and discussion}

\subsection{Infrared spectra of the bulk s-PS ranging from 940 to $820 \mathrm{~cm}^{-1}$}

We are particularly interested in the range from 940 to $820 \mathrm{~cm}^{-1}$, which is highly sensitive to chain packing for the s-PS polymorph [9,13-15]. Table 1 summarizes the specific absorbance of s-PS in IR spectrum ranging from 940 to $820 \mathrm{~cm}^{-1}[5,13]$. The specific peaks of the amorphous phase are at 905 and $841 \mathrm{~cm}^{-1}$. The specific peaks of the $\alpha$-form are at 901 (shifted from $905 \mathrm{~cm}^{-1}$ ) and 851 (shifted from $841 \mathrm{~cm}^{-1}$ ) $\mathrm{cm}^{-1}$ [5], while the specific peaks of the $\beta$-form are at 911 (shifted from $905 \mathrm{~cm}^{-1}$ ) and 858 (shifted from $841 \mathrm{~cm}^{-1}$ ) $\mathrm{cm}^{-1}$, respectively.

Figs. 1 and 2 exhibit infrared spectra of the bulk s-PS sample with different thermal histories. Fig. 1a shows two characteristic infrared bands at 905 and $841 \mathrm{~cm}^{-1}$, corresponding to the amorphous phase of the quenched s-PS $[5,13]$. There are two newborn bands appearing at 911 and $858 \mathrm{~cm}^{-1}$ corresponding to the $\beta$-crystal, as shown in Fig. $1 \mathrm{~b}$. This $\beta$-crystal s-PS sample was crystallized from the melt at $240^{\circ} \mathrm{C}$ for $6 \mathrm{~min}$ and then quenched by LN. It is well known that the thermodynamically favored $\beta$-crystal of bulk s-PS is formed through melt-crystallization at a higher temperature $[16,17]$. The same initial sample in Fig. $1 \mathrm{~b}$ is continued to heated to $264^{\circ} \mathrm{C}$ from $30^{\circ} \mathrm{C}$ with a rate of $10^{\circ} \mathrm{C} / \mathrm{min}$ then quenched by $\mathrm{LN}$, and its IR spectrum is showed in Fig. 1c. Peaks at 901 and $851 \mathrm{~cm}^{-1}$ corresponding to the $\alpha$-crystal are also observed in Fig. 1c.

Fig. 2 shows the FTIR spectra of s-PS bulk samples ranging from 865 to $820 \mathrm{~cm}^{-1}$ that have been cooled at different cooling rates from $-1^{\circ} \mathrm{C} / \mathrm{min}$ to $-100^{\circ} \mathrm{C} / \mathrm{min}$. The dashed lines of Fig. $2 \mathrm{e}$ show the result of curve fitting ranging from 865 to $820 \mathrm{~cm}^{-1}$. Both $\alpha$ - and $\beta$-crystals are present in these cooled s-PS samples. The characteristic $\alpha$ crystal peaks (901 and $851 \mathrm{~cm}^{-1}$ ) become more evident with the increase of the cooling rate.

By cooling at a slower rate, the crystallizing chains can be packed into more favorable into $\beta$-crystals at high temperature and longer duration. Therefore, the crystallizable portion of the s-PS (in melt state) is considerably less for

Table 2

Curve-fitting results of the ranging $865-820 \mathrm{~cm}^{-1}$ of s-PS IR spectra

\begin{tabular}{|c|c|c|c|c|c|c|c|c|c|c|c|}
\hline \multirow[t]{2}{*}{ Sample } & \multicolumn{3}{|c|}{ Amorphous phase } & \multicolumn{3}{|c|}{$\beta$-Crystal } & \multirow[t]{2}{*}{ Abs. ratio, $a_{\beta}$} & \multicolumn{3}{|c|}{$\alpha$-Crystal } & \multirow[t]{2}{*}{ Abs. ratio, $a_{\alpha}$} \\
\hline & Area & Freq. ${ }^{\mathrm{a}}\left(\mathrm{cm}^{-1}\right)$ & Width $^{\mathrm{b}}$ & Area & Freq. ${ }^{a}\left(\mathrm{~cm}^{-1}\right)$ & Width $^{\mathrm{b}}$ & & Area & Freq. ${ }^{\mathrm{a}}\left(\mathrm{cm}^{-1}\right)$ & Width $^{\mathrm{b}}$ & \\
\hline 1 & $\begin{array}{l}2.322 \\
1.341 \\
1.498\end{array}$ & $\begin{array}{l}841.1 \\
840.8 \\
840.7\end{array}$ & $\begin{array}{l}10.4 \\
10.3 \\
10.4\end{array}$ & 0.273 & 857.8 & 4.1 & 0.278 & 0.142 & 851.4 & 3.5 & 0.173 \\
\hline 2 & $\begin{array}{l}1.115 \\
0.608 \\
0.706\end{array}$ & $\begin{array}{l}841.1 \\
840.9 \\
840.7\end{array}$ & $\begin{array}{l}10.3 \\
10.1 \\
10.2\end{array}$ & 0.137 & 857.8 & 3.9 & 0.270 & 0.072 & 851.3 & 3.3 & 0.176 \\
\hline 3 & $\begin{array}{l}1.240 \\
0.742 \\
0.842\end{array}$ & $\begin{array}{l}841.2 \\
840.8 \\
840.6\end{array}$ & $\begin{array}{l}10.4 \\
10.2 \\
10.8\end{array}$ & 0.134 & 857.9 & 3.6 & 0.268 & 0.071 & 851.1 & 3.3 & 0.178 \\
\hline 4 & $\begin{array}{l}0.916 \\
0.544 \\
0.642\end{array}$ & $\begin{array}{l}841.3 \\
840.8 \\
840.6\end{array}$ & $\begin{array}{l}10.6 \\
11.0 \\
10.5\end{array}$ & 0.101 & 857.9 & 4.0 & 0.272 & 0.050 & 851.6 & 3.1 & 0.180 \\
\hline 5 & $\begin{array}{l}0.652 \\
0.372 \\
0.371\end{array}$ & $\begin{array}{l}840.8 \\
840.8 \\
840.8\end{array}$ & $\begin{array}{l}10.4 \\
10.6 \\
10.9\end{array}$ & 0.076 & 857.8 & 4.2 & 0.273 & 0.052 & 851.6 & 3.3 & 0.184 \\
\hline 6 & $\begin{array}{l}1.202 \\
0.699 \\
0.794\end{array}$ & $\begin{array}{l}840.9 \\
840.7 \\
840.9\end{array}$ & $\begin{array}{l}10.5 \\
10.4 \\
10.5\end{array}$ & 0.136 & 857.8 & 4.0 & $\begin{array}{l}0.271 \\
\text { Avg. } \\
=0.272 \pm 0.005\end{array}$ & 0.073 & 851.3 & 3.5 & $\begin{array}{l}0.179 \\
\text { Avg. } \\
=0.178 \pm 0.005\end{array}$ \\
\hline
\end{tabular}

${ }^{a}$ Wavenumber.

${ }^{\text {b }}$ Width at half-height $\left(\mathrm{cm}^{-1}\right)$. 


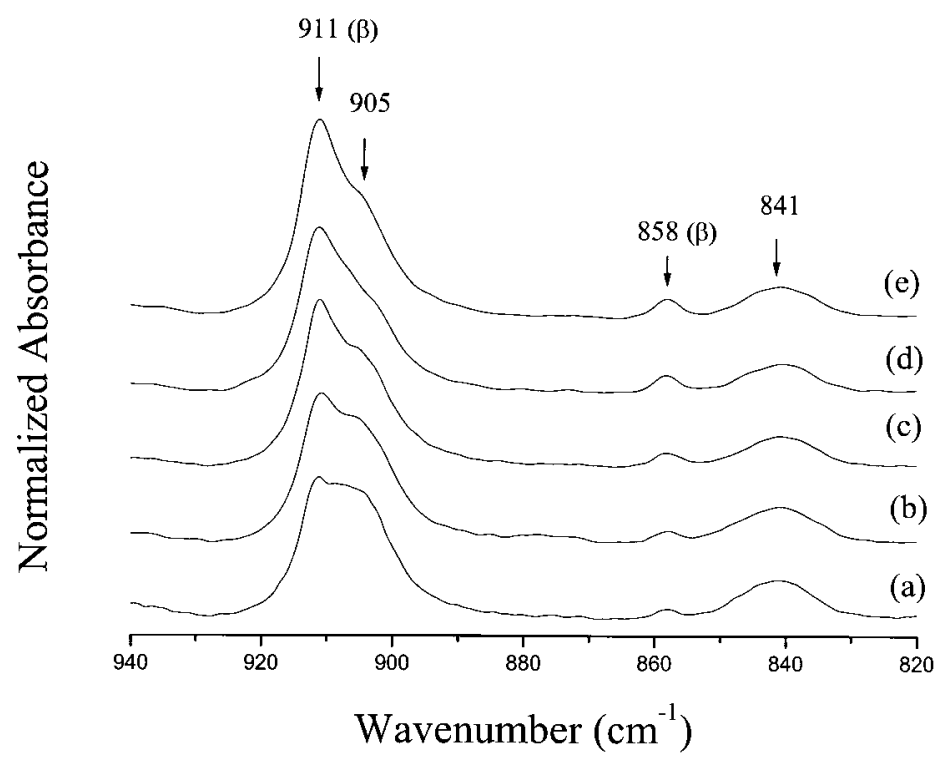

Fig. 4. FTIR spectra of melt-crystallized isothermally s-PS thin film sample at $240^{\circ} \mathrm{C}$ for: (a) 2 ; (b) 6 ; (c) 10 ; (d) 60 ; and (e) $240 \mathrm{~min}$.

further crystallization into the $\alpha$-crystal at lower temperature and slower cooling rate. On the contrary, the polymer chains retain more crystallizable portion available for packing into the $\alpha$-crystal at lower temperature and faster cooling rate, as shown in Fig. 2e.

The peak intensities of 905 and $841 \mathrm{~cm}^{-1}$ (corresponding to amorphous phase) are decreased at the expense of growing peak intensities of bands at 901, 851 ( $\alpha$-crystal) or/and 911, $858 \mathrm{~cm}^{-1}$ ( $\beta$-crystal). This result provides the evidence on the effect of thermal history upon the polymorph change of the s-PS from FTIR spectra. Furthermore, the thermodyna- mically favored $\beta$-crystal dominates throughout the long isothermal durations in bulk s-PS sample.

\subsection{Quantitative measurement of crystallinity on $\alpha$ - and $\beta$ - crystals}

The melt-crystallization temperature as well as the specimen thickness can significantly affect the relative fractions of different crystal forms. In our previous report, the $\alpha$ - to $\beta$ crystal transformation observed usually does not occur in the cold-crystallization process in the thin film s-PS sample

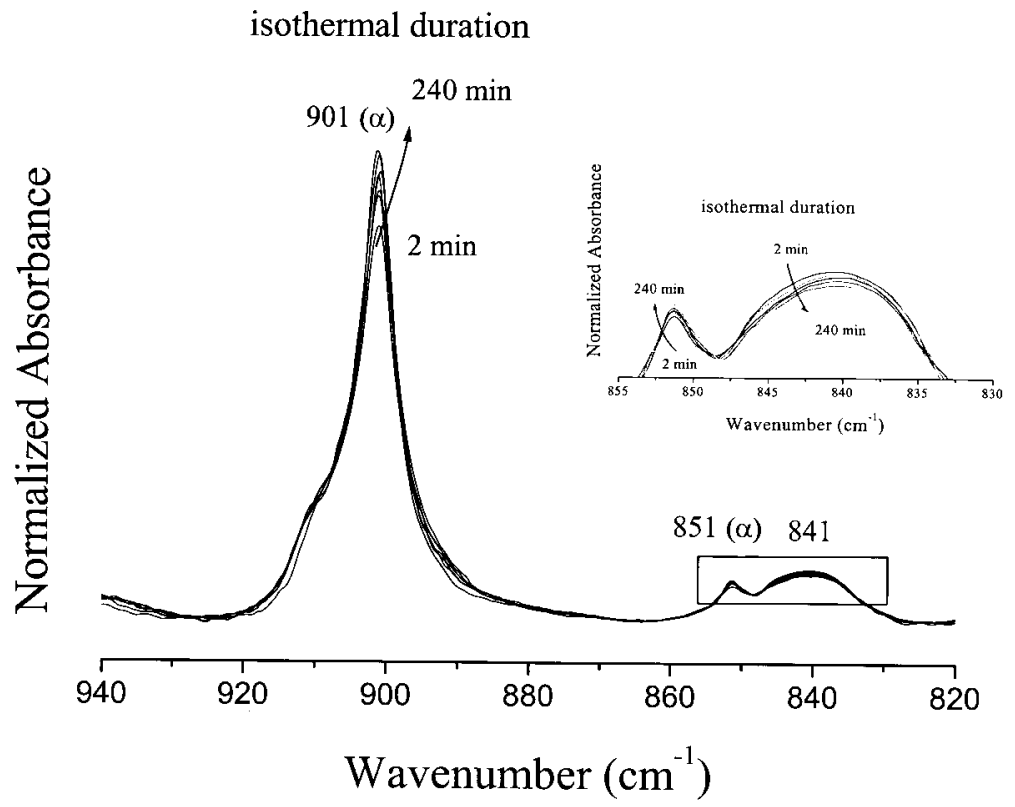

Fig. 5. FTIR spectra of cold-crystallized isothermally s-PS thin film at $240^{\circ} \mathrm{C}$ for: (a)2; (b) 4; (c) 6; (d) 10; (e) 60; and (f) 240 min. 
Table 3

The results of curve-fitting ranging between 865 and $820 \mathrm{~cm}^{-1}$, crystallinity of melt-crystallized s-PS with various isothermal duration at $240^{\circ} \mathrm{C}$ obtained from Fig. 4

\begin{tabular}{|c|c|c|c|c|c|c|c|}
\hline \multirow{2}{*}{$\begin{array}{l}\text { Melt-crystallization } \\
\text { isothermal time ( } \mathrm{min})\end{array}$} & \multicolumn{3}{|c|}{ Amorphous phase } & \multicolumn{3}{|c|}{$\beta$-Crystal } & \multirow{2}{*}{$\begin{array}{l}\text { Crystallinity } \\
\left(C_{\beta}, \%\right)^{\mathrm{a}}\end{array}$} \\
\hline & Area & Freq. ${ }^{\mathrm{b}}\left(\mathrm{cm}^{-1}\right)$ & Width $^{\mathrm{c}}$ & Area & Freq. ${ }^{\mathrm{b}}\left(\mathrm{cm}^{-1}\right)$ & Width $^{\mathrm{c}}$ & \\
\hline 2 & 0.439 & 841.3 & 11.1 & 0.043 & 858.1 & 3.3 & 26.3 \\
\hline 6 & 0.423 & 840.5 & 11.0 & 0.057 & 857.9 & 3.6 & 33.1 \\
\hline 10 & 0.448 & 841.1 & 9.99 & 0.066 & 857.9 & 3.6 & 35.1 \\
\hline 60 & 0.347 & 841.0 & 10.9 & 0.054 & 857.7 & 3.7 & 36.6 \\
\hline 240 & 0.377 & 840.8 & 10.7 & 0.068 & 857.2 & 4.7 & 38.3 \\
\hline
\end{tabular}

\footnotetext{
a Absorptivity ratio $=0.272$.

${ }^{\mathrm{b}}$ Wavenumber.

c Width at half-height $\left(\mathrm{cm}^{-1}\right)$.
}

Table 4

The results of curve-fitting ranging between 865 and $820 \mathrm{~cm}^{-1}$, crystallinity of cold-crystallized s-PS with various isothermal duration at $240^{\circ} \mathrm{C}$ obtained from Fig. 5

\begin{tabular}{|c|c|c|c|c|c|c|c|}
\hline \multirow{2}{*}{$\begin{array}{l}\text { Cold-crystallization } \\
\text { isothermal time ( } \mathrm{min})\end{array}$} & \multicolumn{3}{|c|}{ Amorphous phase } & \multicolumn{3}{|c|}{$\alpha$-Crystal } & \multirow{2}{*}{$\begin{array}{l}\text { Crystallinity } \\
\left(C_{\alpha}, \%\right)^{\mathrm{a}}\end{array}$} \\
\hline & Area & Freq. ${ }^{\mathrm{b}}\left(\mathrm{cm}^{-1}\right)$ & Width $^{c}$ & Area & Freq. ${ }^{\mathrm{b}}\left(\mathrm{cm}^{-1}\right)$ & Width $^{\mathrm{c}}$ & \\
\hline 2 & 1.123 & 840.9 & 12.3 & 0.153 & 851.9 & 3.3 & 43.4 \\
\hline 4 & 1.146 & 840.8 & 11.7 & 0.199 & 851.8 & 3.2 & 49.4 \\
\hline 6 & 1.033 & 840.5 & 11.3 & 0.199 & 851.4 & 3.3 & 52.0 \\
\hline 10 & 1.086 & 841.0 & 12.1 & 0.225 & 851.9 & 3.7 & 53.7 \\
\hline 60 & 1.570 & 840.6 & 11.0 & 0.371 & 851.9 & 3.3 & 57.0 \\
\hline 240 & 0.311 & 841.0 & 11.1 & 0.077 & 851.7 & 3.3 & 58.2 \\
\hline
\end{tabular}

\footnotetext{
${ }^{\text {a }}$ Absorptivity ratio $=0.178$.

b Wavenumber.

c Width at half-height $\left(\mathrm{cm}^{-1}\right)$.
}

(less than $10 \mu \mathrm{m}$ ), instead, $\alpha$-crystal is formed [7]. The thermodynamically favored transformation, $\alpha$ - to $\beta$ - crystal, is effectively inhibited by the physical hindrance in the very thin film s-PS sample. It provides a convenient way to distinguish the crystallization behavior of s-PS $\alpha$ - and $\beta$ crystals.

Fig. 3a-c show FTIR spectra ranging from 865 to $820 \mathrm{~cm}^{-1}$ of the quenched, cold-crystallized (at $240^{\circ} \mathrm{C}$ ) and melt-crystallized (at $240^{\circ} \mathrm{C}$ ) s-PS thin films. Fig. 3a exhibits the amorphous peak at $841 \mathrm{~cm}^{-1}$. The $\alpha$-crystal peak at $851 \mathrm{~cm}^{-1}$ and $\beta$-crystal peak at $858 \mathrm{~cm}^{-1}$ appear in the cold-crystallized and melt-crystallized s-PS thin film samples, as shown in Fig. $3 \mathrm{~b}$ and c, respectively. Curve fitting ranging between 865 and $820 \mathrm{~cm}^{-1}$ shows two Gaussian peaks that provides an adequate fit for systems of cold- and melt-crystallization as shown in the dash-lines of Fig. 3. Unique method can be used to determine the absorptivity ratio of respective absorbances of $\alpha$-crystal/ amorphous and $\beta$-crystal/amorphous. This approach is based on the fact that certain fraction of the $841 \mathrm{~cm}^{-1}$ "amorphous" peak has transformed into the $851 \mathrm{~cm}^{-1}$ " $\alpha$-crystal" peak and the $858 \mathrm{~cm}^{-1}$ " $\beta$-crystal" peak after melt- and cold-crystallizations, respectively. Hence the following equations can be used to determine both absorptivity ratios

$$
\begin{aligned}
& a_{\alpha}=\left(A_{851}\right) /\left(A_{841}^{*}-A_{841 \alpha}\right) \\
& a_{\beta}=\left(A_{858}\right) /\left(A_{841}^{*}-A_{841 \beta}\right)
\end{aligned}
$$

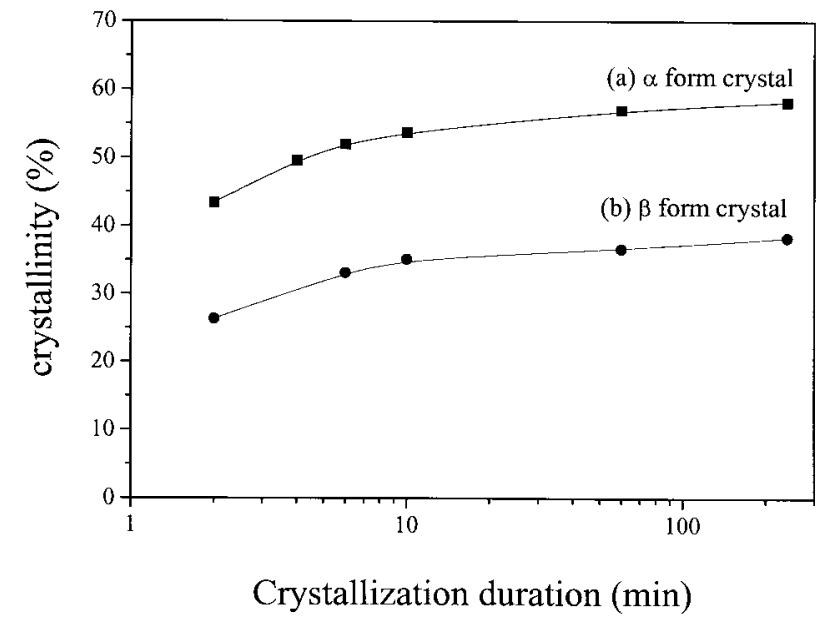

Fig. 6. Relationship of crystallinity and crystallization duration for exclusive: (a) $\alpha$-; and (b) $\beta$-crystal which isothermally crystallized at $240^{\circ} \mathrm{C}$. 
where $a_{\alpha}$ and $a_{\beta}$ are the ratios of absorptive coefficients of $A_{851} / A_{841}$ and $A_{858} / A_{841}$ for $\alpha$ - and $\beta$-crystal absorbances. $A_{841}^{*}$ represents the amorphous area of the quenched s-PS while $A_{851}$ and $A_{841 \alpha}$ are the respective areas of $\alpha$-crystal and amorphous after cold-crystallization. $A_{858}$ and $A_{841 \beta}$ are respective areas of $\beta$-crystal and amorphous after melt-crystallization. Six samples with different thermal histories were examined by the above method, and results of curve fitting are given in Table 2. The average values of these absorptivity ratios, $a_{\alpha}$ and $a_{\beta}$, are found to be constant for different samples, $0.178 \pm 0.005$ and $0.272 \pm 0.005$ for $\alpha$ - and $\beta$-crystal absorbances, respectively. The success of this method requires that the amount of sample in the infrared beam must remain constant and the extent of transformation from the amorphous to " $\alpha-$-" or " $\beta$-" crystal is large to minimize error.

The crystallinities of $\alpha$ and $\beta$-crystals of the s-PS can be obtained from the following equations:

$C_{\alpha}=\frac{A_{851} / a_{\alpha}}{A_{841}+A_{851} / a_{\alpha}+A_{858} / a_{\beta}} \times 100 \%$

$C_{\beta}=\frac{A_{858} / a_{\beta}}{A_{841}+A_{851} / a_{\alpha}+A_{858} / a_{\beta}} \times 100 \%$

where $C_{\alpha}$ and $C_{\beta}$ represent the crystallinities of $\alpha$ and $\beta$ crystals, respectively. Therefore, the determination of infrared absorptivity ratios makes it possible to obtain the fractions of amorphous, $\alpha$ - and $\beta$ - crystals of any s-PS sample.

\subsection{Crystallization processes of $\alpha$ - and $\beta$-crystals}

Fig. 4 shows the FTIR spectra of the isothermally meltcrystallized s-PS thin film sample at $240^{\circ} \mathrm{C}$ for $2,6,10,60$ and $240 \mathrm{~min}$, respectively. The intensities of amorphous phase peaks (905 and $841 \mathrm{~cm}^{-1}$ ) decrease with increasing the isothermal duration at $240^{\circ} \mathrm{C}$, while intensities of $\beta$ crystal peaks $\left(911\right.$ and $858 \mathrm{~cm}^{-1}$ ) increase. It indicates that the crystallinity of the $\beta$-crystal increases with increasing the isothermal heating duration at $240^{\circ} \mathrm{C}$. However, the $\alpha$-crystal peaks are absent in the melt-crystallized s-PS sample at $240^{\circ} \mathrm{C}$.

Fig. 5 shows the FTIR spectra of the isothermally coldcrystallized s-PS thin films at $240^{\circ} \mathrm{C}$ for $2,4,6,10,60$ and 240 min, respectively. The intensity of amorphous phase peak $\left(841 \mathrm{~cm}^{-1}\right)$ decreases with increasing cold-crystallization duration at $240^{\circ} \mathrm{C}$. The $\beta$-crystal peaks are absent in this cold-crystallized s-PS thin film sample. The intensities of $\alpha$ crystal peaks (901 and $851 \mathrm{~cm}^{-1}$ ) increase with increasing the isothermal heating duration at $240^{\circ} \mathrm{C}$. This implies that the crystallinity of the $\alpha$-crystal increases at $240^{\circ} \mathrm{C}$ with increasing cold-crystallization duration. In the two-phase model, the isosbestic point should be observed in $\sim 847 \mathrm{~cm}^{-1}$, however, it was not observed in the present spectra due to signal noise.

Table 3 summaries the results of curve-fitting ranging from 865 to $820 \mathrm{~cm}^{-1}$, where crystallinity of the melt- crystallized s-PS with various isothermal durations at $240^{\circ} \mathrm{C}$ are obtained from Fig. 4. Table 4 summaries the same parameters in Table 3 for the cold-crystallized s-PS with various isothermal durations at $240^{\circ} \mathrm{C}$ obtained from Fig. 5. As would be expected, the crystallinities of $\alpha$ - and $\beta$ crystals increase with the increase of thermal duration on cold- and melt-crystallization, respectively. Fig. 6 shows the relationship of crystallinity versus crystallization duration for $\alpha$ - and $\beta$-crystals isothermally crystallized at $240^{\circ} \mathrm{C}$ from cold- and melt-crystallizations based on results from Tables 3 and 4, and Eqs. (3) and (4). There is an apparent turning point in both curves in Fig. 6, since the crystallinities of both $\alpha$ - and $\beta$ - crystals are approaching their limit values. The crystallinity of the $\alpha$-crystal is significantly higher than the $\beta$-crystal in the thin film sample crystallized at $240^{\circ} \mathrm{C}$ for the same duration. The rate of crystallization of $\alpha$-crystal in cold-crystallization is higher than that of the melt-crystallized $\beta$-crystal, reflecting on the kinetically favored $\alpha$-crystal for crystallization process at $240^{\circ} \mathrm{C}$ in thin film sample.

\section{Conclusions}

This study provides a novel method to determine crystallinities of the $\alpha$ - and $\beta$-crystals of s-PS by FTIR with sufficient accuracy for the first time. The cold-crystallized thin film s-PS sample results in exclusively $\alpha$-crystal, the usually observed crystal transformation of $\alpha$ - to $\beta$-crystal in s-PS bulk sample is effectively inhibited. The absence of crystal transformation of $\alpha$ - to $\beta$-crystal provides a convenience way to study the crystallization behavior and crystallinity of s-PS.

The peak corresponding to $\alpha-\left(858 \mathrm{~cm}^{-1}\right)$ or $\beta$ $\left(851 \mathrm{~cm}^{-1}\right)$ crystal is shifted from the amorphous peak $\left(841 \mathrm{~cm}^{-1}\right)$ in FTIR spectrum. The absorptivity ratio of respective absorbances of " $\alpha$-crystal/amorphous- $a_{\alpha}$ " and " $\beta$-crystal/amorphous- $a_{\beta}$ " are found to be $0.178 \pm 0.005$ and $0.272 \pm 0.005$, respectively. The $\alpha$-crystal is more kinetically favorable and the $\beta$-crystal is more thermodynamically favorable.

\section{Acknowledgements}

This financial support of this research was provided by National Science Council, Taiwan, under Contract No. NSC-88-2116-E-009-006

\section{References}

[1] Guerra G, Vitagliano VM, De Rosa C, Petraccone V, Corradini P. Macromolecules 1990;23:1539.

[2] De Rosa C, Rapaccuolo M, Guerra G, Petraccone V, Corradini P, Polymer . 33 1992;7:1423.

[3] Rosa C, Guerra G, Petraccone V, Corradini P. Polym J 1991;23:1435.

[4] Handa YP, Zhang Z, Wong B. Macromolecules 1997;30:8499. 
[5] Wu HD, Tseng CR, Chang FC. Macromolecules 2001 (in press).

[6] Sun YS, Woo EM. Macromolecules 1999;23 and 32:7836.

[7] Wu HD, Wu ID, Chang FC. Macromolecules 2000;33:8915.

[8] Strobl GR, Hagedorn W. J Polym Sci, Polym Phys Ed 1978;16:1181.

[9] Kellar EJC, Galiotis C, Andrews EH. Macromolecules 1996;29:3515.

[10] Vittoria V, Ruvolo Filho A, De Candia F. J Macromol Sci, Phys B 1990;29:411.

[11] Kellar EJC, Evan AM, Knowles J, Galiotis C, Andrews EH. Macromolecules 1997;30:2400.
[12] Vittoria V. Polym Commun 1990;31:263.

[13] Pellecchia C, Longo P, Grassi A, Ammendola P, Zambelli A. Markromol Chem, Rapid Commun 1987;8:277.

[14] Musto P, Tavone S, Guerra G, De Rosa C. J Polym Sci B, Polym Phys 1997;35:1055.

[15] Vittoria V, Ruvolo Filho A, De Candia F. J Macromol Sci, Phys B 1990;29:411.

[16] Woo EM, Wu FS. Macromol Chem Phys 1998;199:2041.

[17] Woo EM, Sun YS, Lee ML. Polymer Commun 1998;40:442. 